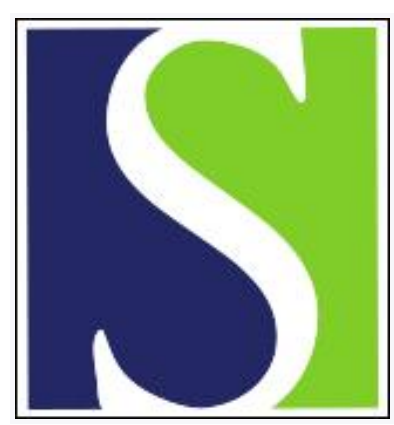

Scand J Work Environ Health 2008;34(3):165-167

https://doi.org/10.5271/sjweh.1239

Issue date: 30 Jun 2008

Moose Consort Strobe and Miame Stard Remark or how can we improve the quality of reporting studies

by Verbeek J

Affiliation: Scandinavian Journal of Work, Environment \& Health, Topeliuksenkatu 41 a A, Fl-00250 Helsinki, Finland. jos.verbeek@ttl.fi

Key terms: editorial; Miame Stard Remark; Moose Consort Strobe; reporting quality

This article in PubMed: www.ncbi.nlm.nih.gov/pubmed/18728905

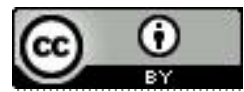




\section{Moose Consort Strobe and Miame Stard Remark or how can we improve the quality of reporting studies}

You probably wonder if the beginning of the title of this editorial is a line of medieval English or a list of cryptic code words from a high-speed thriller. No, these are all acronyms of workgroups that promote better quality in the reporting of scientific articles. Each acronym stands for a guideline about reporting a specific type of study (1-7). For the field of occupational health also the Trend and Quorom statements are of importance $(8,9)$. The number of guidelines is still increasing. The most exhaustive source of reporting guidelines is probably the Equator Network [Equator Network. Equator network: enhancing the quality and transparency of health research (Internet). Oxford (United Kingdom): Equator Network (cited 2 June 2008). Available from: www.equator-network.org]. One might wonder, however, whether there is actually a need for all these guidelines and whether they work.

I have been discussing the quality of reporting with many readers and writers of scientific articles. Most of them acknowledge that there are often problems in understanding the findings of studies.

Let me take the case of the reader. If a reader is an ordinary practicing occupational physician who wants to keep up to date with the science in his or her field, he or she is expected to read a scientific journal. For most physicians, reading and understanding an article is one thing, but critically reading and appraising it is another. Usually, it is too quickly assumed that one is not clever enough to understand a study's complicated results when actually the reporting is unclear. Therefore, many readers take the conclusions of the authors at face value, and usually that is not a wise approach. This is not to say that most authors intentionally mislead their readership, but they do have to compete for limited space in high-quality journals. Therefore, authors do their best to polish their findings to the highest possible level. As we all know, most people prefer good news to bad news and therefore authors try to promote their findings as a positive result. If you do not believe me, try to get negative results published. This is one reason why we need guidelines for authors. They should guarantee that readers get sufficient information to be able to critically appraise articles.

Actually, the case of authors is not very different. First of all, authors are faced with the task of convincing the editor and reviewers of scientific journals that their study is worth publishing. But how do they accomplish this feat? There are courses in scientific writing that they can take, and reading a book on the topic might help, but still they are confronted with many details, specific to their study, that will not be dealt with. How to report the number of eligible participants or the number lost to follow-up, for instance, and what to write about the basic characteristics of the participants in the study. These are just a few examples of information that will enable a reader to critically appraise the study. Giving too little information could be misleading the reader, but giving too much information could overemphasize a futile problem. That is another reason why we need guidelines for authors. Each author should not have to reinvent the wheel.

So apparently there is a need for reporting guidelines. Guidelines have been carefully prepared and published, but do journals actually use them and do authors follow them? Most journals refer to the guidelines prepared by the International Committee of Medical Journal Editors (ICMJE). Interestingly, the ICMJE has been formed from a small workgroup of general medical journals and is not an open membership organization. The ICMJE has published a document called Uniform Requirements for Manuscripts Submitted to Biomedical Journals: Writing and Editing for Biomedical Publication, which is the document that presents the standard rules. Our journal also refers to this document as the main instruction for 
authors. This document gives general instruction as to manuscript preparation, but the editors also refer to specific guidelines for specific study types like Moose, Consort, and the like. Therefore, apparently, most journals endorse the guidelines for authors that have been developed by these various workgroups. A recent survey on the implementation of the Consort statement in 165 major biomedical journals showed that $42 \%$ referred to this document in their instructions for authors. However, only $38 \%$ referred directly to the Consort statement. Nevertheless this number is a big increase from that of a similar survey carried out in 2003 (10). The fact is we have not made things easy for authors. As an author, one still has to go through many webpages and a long and tedious document to find out these things.

Another way to find out if authors really do comply with reporting guidelines is to check the quality of published articles. In our journal we deal mostly with observational studies of the relation between risk factors at work and occupational diseases, disability, or injuries. Here, the Strobe guideline, which has been published recently in a number of major medical journals, would apply (4). The Strobe guideline has been elaborated by a workgroup of nine international experts who are all senior scientists with a long list of publications. For every section of an article, including the title and acknowledgments, Strobe gives detailed recommendations about the contents, which are further elucidated by examples. Many of these recommendations are based on common sense. Strobe, for example, recommends indicating the study design with a commonly used term in the title or the abstract. This will help readers to easily identify such a key feature. It also helps in indexing the study correctly in electronic databases, which in turn aids searches for information. Another recommendation is to provide key results in the abstract in a numerical form, including numbers of participants, estimates of associations, and appropriate measures of variability and uncertainty, such as odds ratios with confidence intervals. I checked if the authors of our journal comply with these basic recommendations. I checked if the study design was indicated in the title or the abstract and if authors gave numerical details of their findings in the abstract in empirical studies published in the Scandinavian Journal of Work, Environment \& Health. From the studies published in 2007, 58\% indicated the design in the title or the abstract and $52 \%$ gave numerical results in the abstract. I think this means that there is still a lot of room for improvement when it comes to reporting.

What are the facilitators and barriers for implementing reporting guidelines? Let's start with the facilitators. It helps that medical editors have endorsed the most important guidelines and that major journals explicitly state that an author has to adhere to these guidelines. It would also help if writing according to the guidelines were made easier, for example, having readymade templates for articles made available to authors would be an option. The template would indicate where to put each bit of necessary information. This standardized way of reporting has already been implemented by the Cochrane Collaboration and has certainly contributed to its success. It is probably both a barrier and a facilitator for the implementation that these guidelines are developed and written up by undetermined groups of senior scientists. For the average author, it is difficult to identify with such select circles and to see that their guidelines are not meant just for themselves but, instead, for all of us. Therefore, it would help to overcome this barrier if the guidelines were popularized and disseminated to a larger audience, for example, by international scientific associations. In the occupational health field, the International Commission on Occupational Health could play such a role. Some say that it is a barrier that the guidelines are guidelines and not standards that have to be strictly adhered to (11). It would probably help if the workgroups on guidelines, together with medical editors, could indicate which parts can be regarded as a guideline and which should be standard.

As for the Scandinavian Journal of Work Environment \& Health, there is still work to do. We will further elaborate our instructions for authors and see to it that authors adhere to them. For authors, therefore, there is no longer the excuse of ignorance-now that they know that they have to pick the guideline that best fits their study and have to adhere to it. Our approach is not meant to be a further harassment of authors; instead it will facilitate the flow of information from authors to readers and improve the understanding of study results. 


\section{References}

1. Stroup DF, Berlin JA, Morton SC, Olkin I, Williamson GD, Rennie D, et al. Meta-analysis of observational studies in epidemiology: a proposal for reporting: meta-analysis of observational studies in epidemiology (MOOSE) group. JAMA. 2000;283(15):2008-12.

2. Altman DG, Schulz KF, Moher D, Egger M, Davidoff F, Elbourne D, et al. The revised CONSORT statement for reporting randomized trials: explanation and elaboration. Ann Intern Med. 2001;134(8):663-94.

3. Consort Group. Consolidated standards of reporting trials [Internet]. Consort Group [cited 2 June 2008]. Available from: www.consort-statement.org.

4. Vandenbroucke JP, von Elm E, Altman DG, Gotzsche PC, Mulrow CD, Pocock SJ, et al. Strengthening the reporting of observational studies in epidemiology (STROBE): explanation and elaboration. PLoS Med. 2007;4(10):e297.

5. Brazma A, Hingamp P, Quackenbush J, Sherlock G, Spellman P, Stoeckert C, et al. Minimum information about a microarray experiment (MIAME) — toward standards for microarray data. Nat Genet. 2001;29(4):365-71.

6. Bossuyt PM, Reitsma JB, Bruns DE, Gatsonis CA, Glasziou PP, Irwig LM, et al. Towards complete and accurate reporting of studies of diagnostic accuracy: the STARD initiative. BMJ. 2003;326(7379):41-4.

7. McShane LM, Altman DG, Sauerbrei W, Taube SE, Gion M, Clark GM. Reporting recommendations for tumour MARKer prognostic studies (REMARK). Eur J Cancer. 2005;41(12):1690-6.

8. Des Jarlais DC, Lyles C, Crepaz N. Improving the reporting quality of nonrandomized evaluations of behavioral and public health interventions: the TREND statement. Am J Public Health. 2004;94(3):361-6.

9. Moher D, Cook DJ, Eastwood S, Olkin I, Rennie D, Stroup DF. Improving the quality of reports of meta-analyses of randomised controlled trials: the QUOROM statement. Quality of Reporting of Meta-analyses. Lancet. 1999;354(9193):1896900.

10. Hopewell S, Altman DG, Moher D, Schulz KF. Endorsement of the CONSORT statement by high impact factor medical journals: a survey of journal editors and journal 'Instructions to Authors'. Trials. 2008;9:20.

11. Burgoon LD. The need for standards, not guidelines, in biological data reporting and sharing. Nat Biotechnol. 2006;24(11):1369-73.

Scandinavian Journal of Work, Environment \& Health

Jos Verbeek, Associate Editor

[E-mail: jos.verbeek@ttl.fi] 
